\title{
Safety of Intravenous Autologous Bone Marrow-Derived Mesenchymal Cell Transplantation in 5 Patients With Reduced Left Ventricular Ejection Fraction
}

\author{
Yukihito Sato, MD; Takashi Kuragaichi, MD; Shunsuke Saga, MD; \\ Hiroyuki Nakayama, MD; Tomoe Obata; Mitsumasa Watanabe, MD; Kie Fujikura; \\ Masatoki Watanabe; Ken-ichiro Hata; Hajime Ohgushi, MD
}

\begin{abstract}
Background: Although intracardiac injection or intracoronary delivery of mesenchymal stem cells (MSCs) has been reported, there have been few studies on the intravenous injection of MSCs, particularly in Japan.

Methods and Results: Five patients with left ventricular ejection fraction (LVEF) $\leq 45 \%$ received $1.0 \times 10^{8}$ MSCs intravenously. The procedure did not induce significant changes in vital signs. One patient had an elevated body temperature after 1 day, but recovered spontaneously. Laboratory tests remained normal for 1 month after cell delivery. Computed tomography was performed after 1-2 years, and there was no evidence of malignancy.
\end{abstract}

Conclusions: In this pilot study of patients with reduced LVEF, intravenous MSC delivery had no adverse effects.

Key Words: Heart failure; Mesenchymal cell; Regeneration therapy

H eart failure is a life-threatening progressive disease, and although optimal pharmacological and non-pharmacological therapies are recommended in clinical guidelines, the prognosis of heart failure remains unacceptably poor. Regeneration therapy is a promising option in this regard. Mesenchymal stem cells (MSCs), cardiac progenitor cells, bone marrow mononuclear cells, skeletal myoblasts, and the recently described induced pluripotent stem cells are candidate cells for transplantation. ${ }^{1-5}$ Cell delivery routes vary and may entail transendocardial or intramyocardial heart injection, transcoronary injection, cell sheets, and intravenous injections. However, no consensus has been reached regarding cell types and methods of cell delivery.

Not only do MSCs have the ability to self-replicate and the potential to differentiate into cardiomyocytes, but they also have complicated biological effects, including (but not limited to) paracrine anti-inflammatory effects, antifibrotic effects, and neovascularization. ${ }^{6,7}$ Nagaya et al reported that, in a rat model of acute myocardial infarction, intravenous injection of bone marrow-derived MSCs markedly reduced the size of the myocardial infarct and improved left ventricular (LV) function, ${ }^{8}$ whereas in a rat model of cardiomyopathy, intramyocardial injection of MSCs improved cardiac function. ${ }^{9}$ This group also reported on the safety of intracardiac injection of autologous MSCs in human chronic heart failure. ${ }^{10} \mathrm{~A}$ recent meta-analysis showed that MSC therapy with various delivery routes improved LV ejection fraction (LVEF) in patients with heart failure.,2,3 However, there are few reports on the intravenous delivery of MSCs in humans. ${ }^{11-13}$

Although intravenous cell delivery is easy and non-invasive, concerns include fatal arrhythmias, shock, infections, or thrombotic disorders. Although a meta-analysis of MSC administration to patients with various diseases has not shown serious side effects, ${ }^{1}$ MSC administration sometimes induces fever, which may trigger acute exacerbation of heart failure. Moreover, the safe cell dose for Japanese patients is unknown. To the best of our knowledge, this report is the first of the intravenous administration of MSCs to Japanese patients with chronic heart failure.

\section{Methods}

\section{Patients}

This pilot study enrolled patients with reduced LVEF. Patients were eligible for inclusion in the study if they were ambulatory with an LVEF $\leq 45 \%$ on baseline echocardiog-

Received July 6, 2021; revised manuscript received July 19, 2021; accepted July 24, 2021; J-STAGE Advance Publication released online August 18, 2021 Time for primary review: 6 days

Department of Cardiology (Y.S., T.K., S.S., H.N.), Department of Clinical Laboratory (T.O.), Department of Hematology (Mi. Watanabe), Hyogo Prefectural Amagasaki General Medical Center, Amagasaki; Japan Tissue Engineering Co., Ltd. (J-TEC), Gamagori (K.F., Ma. Watanabe, K.H.); and Department of Orthopedic Surgery, Ookuma Hospital, Nagoya (H.O.), Japan

Mailing address: Yukihito Sato, MD, Department of Cardiology, Hyogo Prefectural Amagasaki General Medical Center, 2-17-77 Higashinaniwa, Amagasaki 660-8550, Japan. E-mail: cardioys@kuhp.kyoto-u.ac.jp

All rights are reserved to the Japanese Circulation Society. For permissions, please e-mail: cr@j-circ.or.jp

ISSN-2434-0790 
raphy, were aged $\geq 20$ years, had B-type natriuretic peptide (BNP) concentrations $>50 \mathrm{pg} / \mathrm{mL}$ and had New York Heart Association (NYHA) Class II/III symptoms at screening. Baseline computed tomography (CT) did not show any tumors in the chest or abdominal cavity in any of the patients. Patients had been receiving stable, tolerated, guideline-directed medical therapy for $\geq 6$ months prior to the MSC isolation procedure.

Patients were excluded from the study if they had had cardiovascular events or had undergone surgery or invasive catheter therapy 6 months prior to cell isolation and if they had preoperative severe valvular, pulmonary, hepatic or renal failure, and a history of malignant disease. For the safety of cell incubation, patients who had previously been infected with hepatitis B virus, hepatitis C virus, human immunodeficiency virus, and syphilis were also excluded from the study.

\section{Cell Isolation and Incubation}

Bone marrow aspirate was obtained from the iliac crest of the patient to accumulate MSCs. The procedure was performed in a clean operating room under local anesthesia with lidocaine.

Under Good Gene, Cellular, and Tissue-based Products Manufacturing practices, MSCs were expanded ex vivo in a cell-processing center (Japan Tissue Engineering Co. Ltd, Gamagori, Japan).

Approximately $40 \mathrm{~mL}$ of the donor-derived bone marrow was used for the culture expansion of MSCs in flasks containing culture medium ( $\alpha$-minimum essential medium with $15 \%$ fetal bovine serum and $20 \mu \mathrm{g} / \mathrm{mL}$ gentamicin, supplemented with $10 \mathrm{ng} / \mathrm{mL}$ Basic fibroblast growth factor). All culture steps were performed at $+37^{\circ} \mathrm{C}$ and in humidified atmospheric oxygen with $5 \% \mathrm{CO}_{2}$. The adherent cells became nearly confluent after 11-14 days and were passaged using a trypsin-like enzyme solution into another flask. After several days, the passaged cells were collected using the trypsin-like enzyme solution and used for transplantation.

As we reported previously, ${ }^{14}$ we analyzed the surface antigens of the cultured bone marrow-derived cells using a FACSCalibur flow cytometer (Becton Dickinson Biosciences, San Jose, CA, USA). These cells were positive for CD13, CD44, and CD90, and negative for CD34, CD45, and HLA-DR, which is indicative of MSCs.

MSCs $\left(1.0 \times 10^{8}\right.$ cells $)$ were administered intravenously to patients over a period of $60 \mathrm{~min}$, and patients stayed at least overnight in hospital.

\section{Study Endpoints}

The primary endpoint was safety assessment. Patients were placed on electrocardiographic monitoring and monitored for vital signs (blood pressure, heart rate, and oxygen saturation) for $1 \mathrm{~h}$ during cell delivery. Routine laboratory blood tests (blood cell counts, aspartate aminotransferase, alanine aminotransferase, and creatinine) were performed on Day 0 (day of transplantation), Day 1, and then after 1 and 6 months, with a change of $>50 \%$ from baseline considered significant. CT was performed 1-2 years after the procedure to address the safety concerns regarding the induction of malignant disease.

The secondary endpoint was long-term efficacy. To assess cardiac effects, we evaluated LVEF and LV volume using echocardiography with the modified Simpson's method before and then 6 months after the procedure. We also

\begin{tabular}{|lc|}
\hline Table 1. Clinical Characteristics & \\
Age (years) & $70.0 \pm 4.0$ \\
Body mass index $\left(\mathrm{kg} / \mathrm{m}^{2}\right)$ & $21.4 \pm 1.2$ \\
No. males/females & $5 / 0$ \\
LVEF $(\%)$ & $29.2 \pm 7.6$ \\
Etiology of heart failure & \\
$\quad$ Ischemic disease & $2(40)$ \\
Postoperative valve disease & $1(20)$ \\
Dilated cardiomyopathy & $2(40)$ \\
Medications & \\
$\beta$-blockers & $5(100)$ \\
ACEI/ARB & $3(60)$ \\
Aldosterone antagonist & $4(80)$ \\
Loop diuretic & $5(100)$ \\
\hline
\end{tabular}

Data are presented as the mean \pm SD or as $n(\%)$. ACEI, angiotensin-converting enzyme inhibitors; ARB, angiotensin II receptor blocker; LVEF, left ventricular ejection fraction.

measured plasma BNP, serum cardiac troponin I, and peak oxygen uptake (peak $\dot{\mathrm{VO}}_{2}$ ) on cardiopulmonary exercise testing as surrogate markers of heart failure. Non-cardiac effects evaluated were body composition (bioelectrical impedance data were obtained using an InBody 720-Biospace [Tokyo, Japan]) and pulse wave velocity (PWV).

\section{Ethical Considerations}

All study procedures were performed in compliance with the principles outlined in the Declaration of Helsinki and the institutional guidelines of Hyogo Prefectural Amagasaki General Medical Center. The study was registered with the University Hospital Medical Information Network (UMIN) Clinical Trials Registry (ID: 000025233) and was approved by the Ethics Committee of the Hyogo Prefectural Amagasaki General Medical Center (27-49) and Gamagori Municipal Hospital Specified Certified Regenerative Medicine Committee (356). Written informed consent was obtained from all patients, and the clinical study was conducted in compliance with the guidelines of the Ministry of Health, Labour and Welfare of Japan.

\section{Statistical Analysis}

Data are expressed as the mean \pm SD. Normally distributed continuous variables were analyzed using t-tests, whereas continuous variables with a skewed distribution were analyzed using the Mann-Whitney U test. Categorical variables are presented as numbers or percentages. Statistical analyses were performed using $\mathrm{JMP}^{\circledR}$ version 10.0 (SAS Institute, Cary, NC, USA).

\section{Results}

\section{Patient Enrollment}

The clinical study was initiated in January 2017, and 5 patients (Table 1) were enrolled for the intravenous administration of $1.0 \times 10^{8} \mathrm{MSCs}$. Patients received stable, tolerated, guideline-directed medical therapy for $\geq 6$ months after MSC delivery.

\section{Safety of Cell Delivery}

Blood pressure, heart rate, and oxygen saturation remained stable (Table 2A), and there were no new-onset arrhyth- 


\begin{tabular}{|c|c|c|c|c|}
\hline A & Baseline & $\begin{array}{l}\text { End of cell } \\
\text { infusion }\end{array}$ & $P$ value & \\
\hline Systolic blood pressure (mmHg) & $115.4 \pm 22.5$ & $107.2 \pm 12.6$ & 0.92 & \\
\hline Diastolic blood pressure $(\mathrm{mmHg})$ & $74.4 \pm 8.0$ & $74.2 \pm 8.5$ & 0.56 & \\
\hline Heart rate (beats/min) & $73.8 \pm 7.6$ & $70.2 \pm 7.3$ & 0.98 & \\
\hline $\mathrm{SpO}_{2}(\%)$ & $97.8 \pm 0.8$ & $97.8 \pm 0.4$ & 0.50 & \\
\hline B & $\begin{array}{c}\text { Day } 0 \\
\text { (cell delivery) }\end{array}$ & 1 day & 1 month & 6 months \\
\hline White blood cells $(/ \mu \mathrm{L})$ & $4,860 \pm 545$ & $5,120 \pm 756$ & $5,460 \pm 740$ & $5,260 \pm 1,031$ \\
\hline Red blood cells $\left(\times 10^{4} / \mu \mathrm{L}\right)$ & $419.4 \pm 53.8$ & $400.4 \pm 67.7$ & $427.6 \pm 56.7$ & $411.4 \pm 63.2$ \\
\hline Platelets $\left(\times 10^{3} / \mu \mathrm{L}\right)$ & $170.2 \pm 31.9$ & $146.6 \pm 20.2$ & $173.6 \pm 48.3$ & $154.6 \pm 18.3$ \\
\hline AST (U/L) & $23.2 \pm 4.0$ & $19.4 \pm 2.0$ & $19.6 \pm 2.5$ & $24.4 \pm 8.0$ \\
\hline $\mathrm{ALT}(\mathrm{U} / \mathrm{L})$ & $15.6 \pm 7.4$ & $13.0 \pm 6.7$ & $14.8 \pm 8.1$ & $17.8 \pm 9.0$ \\
\hline LDH (U/L) & $227.4 \pm 75.9$ & $211.2 \pm 87.0$ & $202.0 \pm 69.2$ & Not measured \\
\hline Creatinine (mg/dL) & $1.4 \pm 0.5$ & $1.3 \pm 0.5$ & $1.4 \pm 0.5$ & $1.5 \pm 0.6$ \\
\hline
\end{tabular}

(A) Unless indicated otherwise, data are presented as the mean $\pm \mathrm{SD}$. (B) Data are presented as the mean $\pm \mathrm{SD}$. ALT, alanine aminotransferase; AST, aspartate aminotransferase; $L D H$, lactate dehydrogenase.

\begin{tabular}{|lccc|}
\hline \multicolumn{2}{|l|}{ Table 3. Changes in Parameters From Before to 6 Months After Cell Implantation } & \\
& Screening & 6 months & P value \\
LVEF $(\%)$ & $29.2 \pm 7.6$ & $28.4 \pm 9.8$ & 0.5 \\
LVEDV $(\mathrm{mL})$ & $180.4 \pm 50.8$ & $186.0 \pm 25.6$ & 0.5 \\
LVESV $(\mathrm{mL})$ & $130.4 \pm 47.5$ & $135.0 \pm 34.2$ & 0.5 \\
BNP $(\mathrm{pg} / \mathrm{mL})$ & $330.6 \pm 290.6$ & $302.8 \pm 324.9$ & 0.59 \\
Troponin I $(\mathrm{pg} / \mathrm{mL})^{\mathrm{A}}$ & $47.3 \pm 20.4$ & $42.6 \pm 15.5$ & 0.63 \\
Peak VंO $\left(\mathrm{mL} \cdot \mathrm{min}^{-1} \cdot \mathrm{kg}^{-1}\right)$ & $17.4 \pm 4.8$ & $17.3 \pm 4.6$ & 0.56 \\
Body weight $(\mathrm{kg})$ & $61.2 \pm 9.9$ & $62.5 \pm 11.0$ & 0.22 \\
Skeletal $\mathrm{muscle} \mathrm{mass}$ & $24.9 \pm 4.1$ & $25.1 \pm 4.2$ & 0.31 \\
Body fat mass & $15.2 \pm 4.6$ & $16.0 \pm 4.3$ & 0.41 \\
Pulse wave velocity $(\mathrm{cm} / \mathrm{s})$ & & & \\
$\quad$ Right & $1,631.6 \pm 534.6$ & $1,431.0 \pm 276.0$ & 0.84 \\
Left & $1,621.8 \pm 547.1$ & $1,433.0 \pm 299.1$ & 0.78 \\
\hline
\end{tabular}

Unless indicated otherwise, data are presented as the mean \pm SD. ${ }^{A} T$ Two patients had troponin I concentrations $<10 \mathrm{pg} / \mathrm{mL}$ (both before and after cell delivery). Therefore, data are shown for 3 patients. LVEDV, left ventricular enddiastolic volume; LVEF, left ventricular ejection fraction; LVESV, left ventricular end-systolic volume.

mias or shock during cell delivery. No abnormalities suggestive of hemolysis, thrombocytopenia, liver dysfunction, and renal dysfunction were found on routine laboratory tests (Table 2B).

\section{Long-Term Follow-up}

After 6 months of observation, no changes were observed in LVEF, LV diastolic and systolic volume on echocardiography, BNP and troponin I concentrations, and peak $\dot{\mathrm{VO}}_{2}$ on the exercise test (Table 3; Figure). CT scans did not show any tumors in the chest or abdominal cavity.

\section{Discussion}

Although many human heart failure studies have been conducted worldwide with numerous types of cells, very few have been conducted in Japan, and these studies involved myoblast sheets, ${ }^{4}$ intramuscular injection of MSCs, ${ }^{10}$ and, recently, intravenous Muse cells. ${ }^{5}$ Moreover, there is limited experience with the intravenous administration of cells in patients with heart failure, mainly because of safety concerns regarding the entrapment of donor cells in the pulmonary circulation and concerns regarding their therapeutic efficacy in the context of low cardiac engraftment. In this preliminary study, a single dose of intravenous autologous $1.0 \times 10^{8}$ MSCs had no adverse effects and was well tolerated in patients with reduced LVEF. However, the administration of MSCs had no effect on the heart failure.

\section{MSCs}

MSC regeneration studies in patients with heart failure have been designed based on the assumption that the benefits of stem cell therapy accrue only from activities derived from cells engrafted in the dysfunctional myocardium. These activities may reflect cells differentiating into cardiac myocytes, stimulating resident cardiac stem cells to expand and to form a greater number of functioning myocytes, or broad paracrine and systemic activities that allow, for example, favorable cardiac remodeling, enhancement of angiogenesis, and decreased apoptosis. ${ }^{6,7}$ Indeed, a meta- 

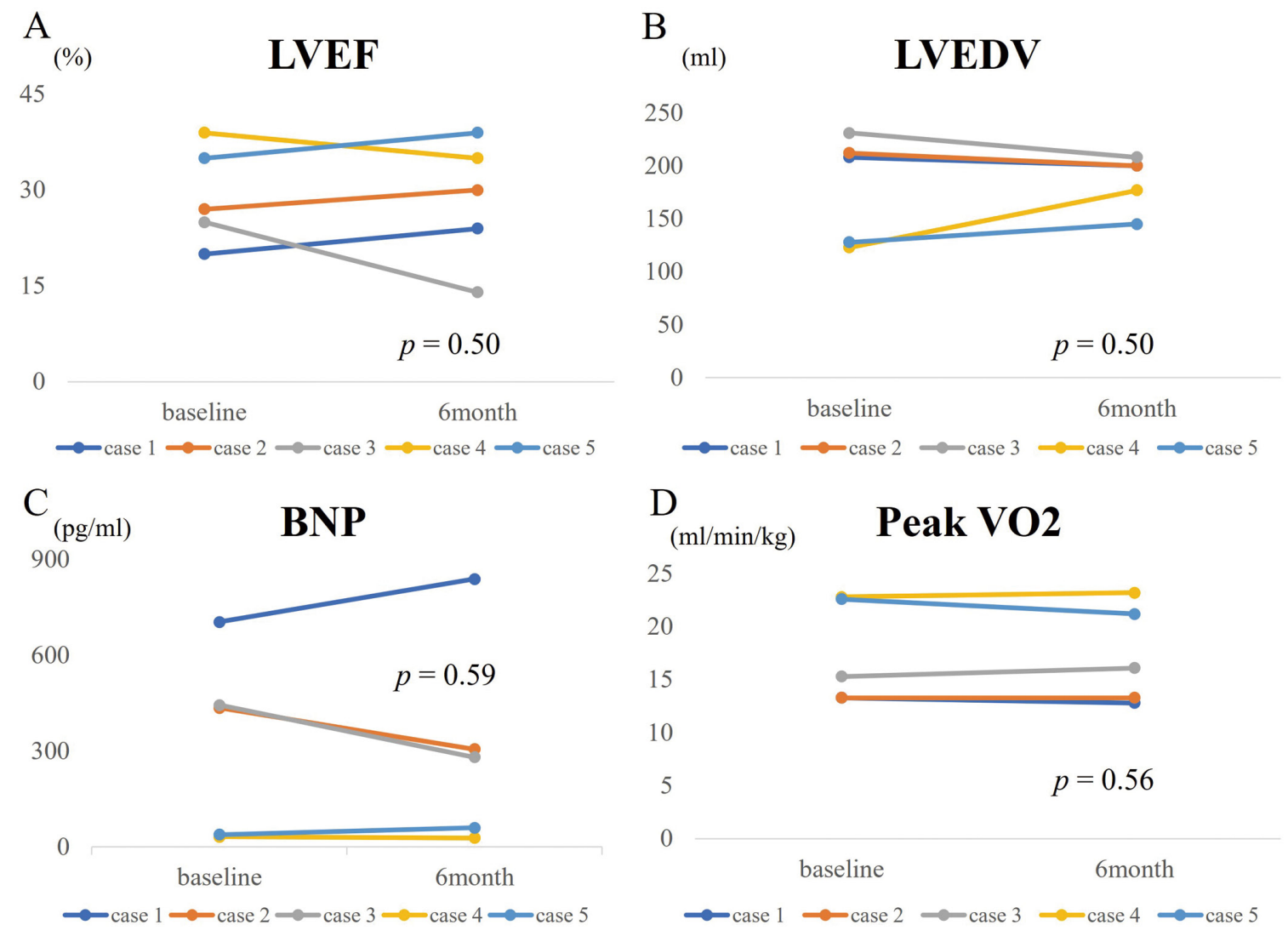

Figure. Changes in (A) left ventricular ejection fraction (LVEF), (B) left ventricular end-diastolic volume (LVEDV), (C) B-type natriuretic peptide (BNP), and (D) peak $\mathrm{V}_{2}$ from baseline to 6 months after cell delivery.

analysis of MSC studies with various delivery routes showed an improvement in LVEF and decreased LV volume in patients with heart failure. , $^{2,3}$

There are 3 routes for cell administration: intravenous infusion, intracoronary injection, and intramyocardial injection. However, intramyocardial cell delivery may result in mechanical myocardial injury or create isolated clusters of injected cells with the potential to introduce myocardial heterogeneity and a risk of arrhythmia. Given the large cell size, intracoronary injection of cells carries a risk of coronary embolization, and ischemic electrocardiographic changes have been reported. Moreover, both procedures require a catheter or surgical technique. The advantages of intravenous administration include technical ease, less invasive nature, and lower costs. However, cell engraftment into the myocardium with intravenous delivery is potentially poor as a result of uptake by lung, hepatic, and splenic tissue. Nevertheless, animal models have shown that MSCs could be engrafted into the myocardium, ${ }^{\mathbf{8}}$ and there are also animal and human studies that have investigated intravenous administration of MSCs with heart failure..$^{\mathbf{8 1 1}-13}$

\section{Safety}

A recent systematic review, including various diseases, did not detect an association between MSC regeneration therapy and the risk of acute infusion toxicity, organ system complications, infection, death, or malignancy. ${ }^{1}$ However, patients with heart failure are very vulnerable to slight changes in vital signs or condition that may lead to severe deterioration. Therefore, careful observations and safety endpoints are very important in addition to efficacy endpoints.

Hare et al performed a double-blind placebo-controlled dose-ranging $\left(0.5,1.6\right.$, and $5 \times 10^{6}$ cells $\left./ \mathrm{kg}\right)$ intravenous allogeneic MSC trial in patients with myocardial infarction;11 Butler et al conducted a single-blind placebo-controlled trial of intravenous allogeneic MSCs $\left(1.5 \times 10^{6}\right.$ cells $\left./ \mathrm{kg}\right)$ for nonischemic cardiomyopathy patients, ${ }^{2}$ and, in RIMECARD (Randomized Clinical Trial of Intravenous Infusion Umbilical Cord Mesenchymal Stem Cells on Cardiopathy), Bartolucci et al intravenously infused umbilical cord-derived MSC $\left(1 \times 10^{6}\right.$ cells $\left./ \mathrm{kg}\right)$ in patients with heart failure. ${ }^{13}$ Serious side effects were not been reported in these trials, which were conducted in Western countries where the body mass index (BMI) of the patients was approximately $30 \mathrm{~kg} / \mathrm{m}^{2}$. In contrast, the BMI of Japanese patients is lower, so a safe dose of intravenous MSCs in Japanese patients needs to be determined.

In the present pilot study, 5 patients received $1.0 \times 10^{8}$ MSCs intravenously. None of the patients experienced a fatal arrhythmia, shock, infections, or clinically apparent thrombotic events, which are safety concerns associated with intravenous cell therapies, although 1 patient had a fever of up to $37.6^{\circ} \mathrm{C}$ that spontaneously recovered. In a 
meta-analysis, Lalu et al reported a significant association between MSCs and transient fever without infection. ${ }^{\mathbf{1}} \mathrm{Lalu}$ et al speculated that the mechanism could be related to an acute inflammatory reaction by a subset of patients to particular preparations of MSCs.

\section{Long-Term Efficacy}

The reason why the patients in this study did not show long-term LVEF improvements is not clear. However, there are some possible reasons. The first is recipient age. Studies raise a clinically relevant issue as to whether recipient age is a crucial factor limiting the response to cell therapy, although some investigators have reported that older recipients did not have an impaired response to MSC therapy.15 The mean age of 70.0 years in the present study was higher than that of other published reports. Second, we used autologous MSCs rather than allogeneic MSCs. It has also been hypothesized that the function of autologous MSCs could be impaired in patients with comorbidities or advanced age. Third is cell dose. In the TRIDENT study, only a high dose of allogeneic MSCs in patients with ischemic cardiomyopathy increased ejection fraction. ${ }^{\mathbf{1 6}}$ Higher doses of cells may result in better improvement. Fourth is the appropriate LV size for cell treatment. The recently conducted CHART-1 study showed a benefit of a reduction in cardiac events in a subset of patients with advanced LV enlargement (baseline LV end-diastolic volume between 200 and $370 \mathrm{~mL}) .{ }^{17}$ Therefore, patients with a relatively small LV size may be excluded.

\section{Future of Intravenous MSC Therapy and Study Limitations}

Although the main effects of MSCs is cardiac, MSCs may improve "non-cardiac systemic effects" independently of the patient's heart condition, perhaps mediated via antiinflammatory properties or angiogenesis. ${ }^{67}$ In addition, intravenous cell delivery may be a suitable delivery method for "repeated regeneration therapy".

A limitation of this study is the small number of patients. However, this sample size is typical of Japanese early phase studies of regeneration therapy for heart failure. ${ }^{5,10}$ Moreover, we did not measure serum fibrinogen, D-dimer, and fibrinogen degradation products (FDP), which focus on pulmonary embolisms. However, our patients showed stable vital signs and no increases in lactate dehydrogenase (LDH) concentrations; LDH is often increased in patients with clinically significant pulmonary embolism..$^{\mathbf{1 8}}$

\section{Sources of Funding}

This study did not receive any specific funding.

\section{Disclosures}

The authors have no conflicts of interest to declare.

\section{IRB Information}

This study was approved by the Ethics Committee of the Hyogo Prefectural Amagasaki General Medical Center (27-49) and Gamagori Municipal Hospital Specified Certified Regenerative Medicine Committee (356).

\section{References}

1. Lalu MM, McIntyre L, Pugliese C, Fergusson D, Winston BW, Marshall JC, et al. Safety of cell therapy with mesenchymal stromal cells (SafeCell): A systematic review and meta-analysis of clinical trials. PLoS One 2012; 7: e47559.

2. Fan M, Huang Y, Chen Z, Xia Y, Chen A, Lu D, et al. Efficacy of mesenchymal stem cell therapy in systolic heart failure: A systematic review and meta-analysis. Stem Cell Res Ther 2019; 10: 150 .

3. Shen T, Xia L, Dong W, Wang J, Su F, Niu S, et al. Systematic review and meta-analysis: Safety and efficacy of mesenchymal stem cells therapy for heart failure. Curr Stem Cell Res Ther 2021; 16: 354-365.

4. Miyagawa S, Domae K, Yoshikawa Y, Fukushima S, Nakamura T, Saito A, et al. Phase I clinical trial of autologous stem cellsheet transplantation therapy for treating cardiomyopathy. $\mathrm{J} \mathrm{Am}$ Heart Assoc 2017; 6: e003918.

5. Noda T, Nishigaki K, Minatoguchi S. Safety and efficacy of human Muse cell-based product for acute myocardial infarction in a first-in-human trial. Circ J 2020; 84: 1189-1192.

6. Bronckaers A, Hilkens P, Martens W, Gervois P, Ratajczak J, Struys T, et al. Mesenchymal stem/stromal cells as a pharmacological and therapeutic approach to accelerate angiogenesis. Pharmacol Ther 2014; 143: 181-196.

7. Ohnishi S, Ohgushi H, Kitamura S, Nagaya N. Mesenchymal stem cells for the treatment of heart failure. Int J Hematol 2007; 86: $17-21$.

8. Nagaya N, Fujii T, Iwase T, Ohgushi H, Itoh T, Uematsu M, et al. Intravenous administration of mesenchymal stem cells improves cardiac function in rats with acute myocardial infarction through angiogenesis and myogenesis. Am J Physiol Heart Circ Physiol 2004; 287: H2670-H2676.

9. Nagaya N, Kangawa K, Itoh T, Iwase T, Murakami S, Miyahara $\mathrm{Y}$, et al. Transplantation of mesenchymal stem cells improves cardiac function in a rat model of dilated cardiomyopathy. Circulation 2005; 112: 1128-1135.

10. Yagyu T, Yasuda S, Nagaya N, Doi K, Nakatani T, Satomi K, et al. Long-term results of intracardiac mesenchymal stem cell transplantation in patients with cardiomyopathy. Circ J 2019; 83: $1590-1599$.

11. Hare JM, Traverse JH, Henry TD, Dib N, Strumpf RK, Schulman $\mathrm{SP}$, et al. A randomized, double-blind, placebo-controlled, doseescalation study of intravenous adult human mesenchymal stem cells (Prochymal) after acute myocardial infarction. J Am Coll Cardiol 2009; 54: 2277-2286.

12. Butler J, Epstein SE, Greene SJ, Quyyumi AA, Sikora S, Kim $\mathrm{RJ}$, et al. Intravenous allogeneic mesenchymal stem cells for nonischemic cardiomyopathy: Safety and efficacy results of a Phase II-A randomized trial. Circ Res 2017; 120: 332-340.

13. Bartolucci J, Verdugo FJ, González PL, Larrea RE, Abarzua E, Goset C, et al. Safety and efficacy of the intravenous infusion of umbilical cord mesenchymal stem cells in patients with heart failure: A Phase 1/2 randomized controlled trial (RIMECARD Trial [Randomized Clinical Trial of Intravenous Infusion Umbilical Cord Mesenchymal Stem Cells on Cardiopathy]). Circ Res 2017; 121: $1192-1204$.

14. Kubo H, Takamura K, Nagaya N, Ohgushi H. The effect of serum on the proliferation of bone marrow-derived mesenchymal stem cells from aged donors and donors with or without chronic heart failure. J Tissue Eng Regen Med 2018; 12: e395-e397.

15. Golpanian S, El-Khorazaty J, Mendizabal A, DiFede DL, Suncion VY, Karantalis V, et al. Effect of aging on human mesenchymal stem cell therapy in ischemic cardiomyopathy patients. J Am Coll Cardiol 2015; 65: 125-132.

16. Florea V, Rieger AC, DiFede DL, El-Khorazaty J, Natsumeda M, Banerjee MN, et al. Dose comparison study of allogeneic mesenchymal stem cells in patients with ischemic cardiomyopathy (the TRIDENT study). Circ Res 2017; 121: 1279-1290.

17. Bartunek J, Terzic A, Davison BA, Behfar A, Sanz-Ruiz R, Wojakowski W, et al. Cardiopoietic stem cell therapy in ischaemic heart failure: Long-term clinical outcomes. ESC Heart Fail 2020; 7: 3345-3354.

18. Tayama E, Ouchida M, Teshima H, Takaseya T, Hiratsuka R, Akasu K, et al. Treatment of acute massive/submassive pulmonary embolism. Circ J 2002; 66: 479-483. 